\title{
LIFE TABLE ESTIMATES OF THE INVASIVE SNAIL $P h y s a$ acuta Draparnaud, 1805, OCCURRING IN INDIA
}

\author{
CHILKA SAHA ${ }^{1}$, SAIDA PARVEEN ${ }^{1}$, JOY CHAKRABORTY ${ }^{1}$, SOUJITA PRAMANIK ${ }^{2}$, \\ GAUTAM ADITYA ${ }^{1,2 *}$
}

${ }^{1}$ Department of Zoology, The University of Burdwan, Golapbag, Burdwan 713104, India; e-mail: gautamaditya2001@gmail.com

${ }^{2}$ Department of Zoology, University of Calcutta, 35 Ballygunge Circular Road, Kolkata 700019, India

${ }^{*}$ Author for correspondence

\begin{abstract}
Saha C., Parveen S., Chakraborty J., Pramanik S., Aditya G.: Life table estimates of the invasive snail Physa acuta Draparnaud, 1805, occurring in India. Ekológia (Bratislava), Vol. 36, No. 1, p. 60-68, 2017.
\end{abstract}

\begin{abstract}
The life table characteristics of the invasive snail Physa acuta were assessed in the laboratory using the individuals occurring in a newly colonised area in Burdwan, West Bengal, India. Using the changes in the shell length and the body weight of the snails as surrogate, the population growth of the snails was estimated along with longevity and the fecundity schedule. The cohort of $P$. acuta lived for a maximum of 22 weeks with a life expectancy $\left(e_{x}\right)$ of 7.27 weeks and the age-specific survivorship being 0.825 . Increment of the shell length of the snails complied with the von Bertalanffy growth equation, $l_{t}=11.75\left(1-\exp ^{-0.17(t-0.06)}\right)$, and the observed and the expected data of the length at time $t\left(l_{t}\right)$ did not vary significantly $(\mathrm{z}$ score $=0.230 ; P=$ 0.818 ; $n=20$ pairs). Following attainment of sexual maturity between 28 and 42 days, oviposition continued till 20 weeks time, with $0.1-10$ eggs laid by each individual. The eggs present per capsule remained between 01 and 11 , whilst the net reproductive rate $\left(R_{0}\right)$, intrinsic rate of increase $\left(r_{m}\right)$ and the finite rate of increase $(\lambda)$ were 116.07, 0.1 and 1.11 , respectively. The observations are similar to those made earlier on the same species but from African and South American continents. The results of the present observation are pioneer in providing the initial studies about the life history of the invasive snail P. acuta in Indian context. Using the present information as a basis, further studies including long-term population monitoring should be initiated to understand the effects of the invasive snail P. acuta in the freshwater ecosystem of West Bengal, India.
\end{abstract}

Key words: Physa acuta, invasive snail, life table, von Bertalanffy growth equation.

\section{Introduction}

The invasive snail Physa acuta Draparnaud, 1805 (Gastropoda: Physidae) has spread through the continents of Asia (Ali, 1993), Africa (Brackenbury, Appleton, 1993; de Kock, Wolmarans, 2007; Appelton, Miranda, 2015), Australia (Zukowski, Walker, 2009), Europe (Semenchenko et al., 2008; Raković et al., 2016) and South America (Núñez, 2010) during 
the past few decades. In India, following the reports on the occurrence of $P$. acuta (Raut et al., 1995), little effort has been made to document the demography, life history and ecology, which are essential indicators to monitor the colonisation pattern in the native ecosystem(Aditya, Raut, 2002a,b,c; Devi et al., 2006, 2008). Studies on the population ecology of invasive snails are required to predict the effects of invasion on the native ecosystems as observed for the golden apple snails Pomacea in different regions of India (Aditya, Raut, 2001a,b, 2005), Philippines (de Brito, Joshi, 2016) and the United States (Lach, Cowie, 1999). Demographic features and reproductive biology of the invasive species are useful parameters to estimate and predict the possible range expansion and subsequent effects on the native ecosystem (Keller et al., 2007; Gherardi, 2007). This has been the basis for the assessment of the life history of invasive freshwater snails including $P$. acuta. Empirical studies on the growth and the reproduction of the snail in South Africa (Brackenbury, Appleton, 1993) and Argentina (Núñez, 2010, 2011) have been useful in comparative assessment of the population demography of the invasive snails in the respective geographical area. In Indian context, information on the life history features and the fecundity of $P$. acuta are yet to be deciphered. Therefore, evaluation of the growth and fecundity of the snail $P$. acuta was carried out to supplement the necessary information required to predict the possible pattern of colonisation and establishment in the invaded ecosystems. Demographic aspects of invasive species provide crucial information on the life history strategies and adaptations that facilitate the range expansion and occupation of newer habitats in the invaded regions (de Kock, Wolmarans, 2007; Semenchenko et al., 2008; Guo et al., 2009; $\mathrm{Ng}$ et al., 2015). Evaluation of the fecundity and population of invasive aquatic molluscs facilitates assessment of the risks associated with invasion (Keller et al., 2007). The studies on the demography of the invasive snails such as Melanoides tuberculata (Elkarmi, Ismail, 2007) and Bellamya chinensis (Stephen et al., 2013) substantiate this proposition. Information on the population biology of the invasive snails has been helpful for predicting the possibilities of range expansion as well as the effects on the native biota (Gotoh, Kawata, 2000). Thus the results of the present study will be useful in understanding the life history strategy of the invasive snail Physa acuta in Indian context as well as make a comparison with the pattern of life cycle observed in different invaded ecosystems.

Until now, few studies have documented the presence of the snails in discrete parts of India. Whilst laboratory studies have been restricted to the identification of the predators against the invasive snails, the population biology including the reproduction and further invasion in the Indian freshwater wetlands are yet to be characterised. Aquatic insects such as the water bugs (e.g., Diplonychus rusticus) (Aditya, Raut, 2002b,c) and the malacophagous leech (e.g., Glossiphonia weberi) (Aditya, Raut, 2002a) have been demonstrated as the predators of the invasive Physa acuta, which may be one of the reasons for their restricted distribution in the sewage drain and associated puddles in Indian region. Even with the assumption of the predators being a factor in reducing the possible colonisation and establishment of the snail in the native freshwater bodies, the assessment of the population growth and fecundity is required to predict the possible mode of population expansion in Indian context. In accordance with the propositions stated above, this compilation is an effort to summarise the observations of the present study on P. acuta in the context of 
earlier studies made in other geographical areas. The results are expected to highlight the generalised life history strategy of $P$. acuta as an invasive species and enable predicting the prospective effects in the freshwater ecosystems of the invaded areas.

\title{
Material and methods
}

\author{
Collection and maintenance of P. acuta
}

The snail $P$. acuta was collected from the sewage drain and associated puddles adjacent to the Golapbag campus of The University of Burdwan, Burdwan, India, following the survey of the area during 2014. The collected individuals of $P$. acuta were brought to the laboratory and segregated into larger $(>9 \mathrm{~mm})$, medium $(7-9 \mathrm{~mm})$ and smaller $(5-7 \mathrm{~mm})$ size classes for rearing. The snails of each size classes were reared in mesocosms (glass aquarium, $32 \times 36 \times 38 \mathrm{~cm}$, filled with $25 \mathrm{~L}$ of tap water, $\mathrm{pH}$ 7.4-7.9) separately with a density of 10 snails/L with lettuce and degrading plant parts being provided as food. Few leaves of the alligator weed (Alternanthera philoxeroides) leaves were placed as additional refuge for oviposition. At the end of every 24-h period, the mesocosms were surveyed for the eggs oviposited and scraped intact and placed in small plastic container filled with tap water for hatching and initiating the experiments. The egg capsules were deposited on the wall of aquaria and in few instances on the leaves. Each egg capsule contained 1-20 eggs and the hatchability remained between 70 and $90 \%$. Using the 0 -day-old hatched juveniles, artificial cohorts consisting of individuals originating from different capsules were built. Thus the $\mathrm{F}_{1}$-generation individuals were considered for the assessment of the life history features of the snail Physa acuta. The life history features of $P$. acuta were assessed using the eggs oviposited by the field collected snails of heterogeneous size group maintained in the laboratory conditions. The 0 -day-old individuals hatching from the eggs were allowed to grow in plastic containers $(500 \mathrm{~mL}$ capacity) supplied with decomposing lettuce. Fifteen individual were considered in each microcosm, and three different replicates were used for the assessment of the growth survivorship and the fecundity of the snails. At the end of each week, the shell length, shell breadth and the body weight were used as surrogate to track the growth of the snails under laboratory conditions. The day of first egg deposition was considered as the age at first reproduction that marked the initiation of the reproductive period of the group. Thus the experiment was carried out using cohorts, each cohort consisting of 15 individuals, and the survivorship was recorded for each cohort each day. The death of the last individual marked the end of the generation of the cohort. To evaluate the longevity, growth and fecundity of the snails, the cohorts of 15 individuals (0-day-old) were reared in 250-mL plastic containers containing 200 $\mathrm{mL}$ of aged tap water. Decomposing leaves of lettuce was added into the rearing container as food for the snail individuals. The water of the containers and the unconsumed food were changed for every $24 \mathrm{~h}$ for the whole experimental period. The number of individuals living was noted and recorded each day to estimate the survivors. At the end of every week, the shell length (SL in millimetres) and the body weight (BW in milligrams) of the snails were noted to monitor the growth. The shell of individual snails was measured using either an ocular micrometer (for the first two weeks) or a divider and scale to the nearest $0.1 \mathrm{~mm}$, and the body weight was measured to the nearest $0.1 \mathrm{mg}$ in a pan balance (Citizen, India). Following the date of attainment of sexual maturity (the day when first egg capsule was noted), the number of eggs oviposited was noted and recorded. Three replicates were considered for the experiments in compliance with the norms of replication, selecting randomly the individuals hatching from the eggs oviposited by different individuals.

\section{Data analysis}

The data on the survivorship was applied to generalised life table parameters (Krebs, 1999), and the age-specific survivorship $\left(l_{x}\right)$ and life expectancy at age $\mathrm{x}\left(e_{x}\right)$ were calculated, whilst the growth of the snails was assessed through the changes in the shell length. The data on the shell length (SL, in $\mathrm{mm}$ ) was portrayed as a function of time and subsequently judged for the compliance (Núñez, 2010) with the von Bertalanffy growth equation $l_{t}=l_{\infty}\left(1-\left(e^{-k\left(t-t_{0}\right)}\right)\right.$, where $l_{t}$ is the shell length of the snails at time $\mathrm{t}$ and $l_{\infty}$ and $k$ are the von Bertalanffy growth parameters. Assuming that the relation between $l_{t+1}$ and $l_{t}$ will yield a straight line equation $(\mathrm{y}=\mathrm{a}+\mathrm{bx})$, with the slope (b) being $e(-k)$ and the intercept (a) being $l_{\infty}=[1-e(-k)]=l_{\infty}(1-\mathrm{b})$, thereby enabling determination of $l_{\infty}$ and $k$, the parameters of the von Bertalanffy growth parameters. The time $t$ is set as the instantaneous time (in weeks in the present study) whilst $\mathrm{t}_{0}$ is obtained as $t_{0}=t+(1 / k) \ln \left(\left(l_{\infty}-l_{t}\right) /\left(l_{\infty}\right)\right)$. Extending the relation between length and the weight as a power law, the growth equation for the body weight $\left(\mathrm{BW}=\mathrm{a} . \mathrm{SL} .^{\mathrm{b}}\right)$ is used as $B W_{t}=B W_{\infty}\left(1-\left(e^{-k\left(t-t_{0}\right)}\right)\right)^{\mathrm{b}}$, where $B W_{\infty}=a . l_{\infty}$. Data of the 250 snails collected from the same habitats were used to construct the equation $B W=a \cdot S L .^{b}$, and the value of $b$ and a was substituted to the equation. Instead of the laboratory population, the population of the snails 
from the field was considered to avoid any bias arising out of the laboratory culture. The data on the expected and observed values of shell length and body weight were compared using the $\mathrm{z}$ - test to judge the fit of the growth data with the von Bertalanffy growth equation. The fecundity schedule was estimated using the following formula (Krebs, 1999) with modifications owing to the hermaphroditic nature of the snails. The $m_{x}$ value was considered without any variations in the sex ratio because of the evidence of self-fertilisation in the species. Although not considered in the present instance, few individuals of the snails when cultured in isolation produced viable eggs that provide the evidence of self-fertilisation. However, the evidence of self-fertilisation is evident in case of hermaphrodite snails prompted to consider the analysis of the fecundity schedule in two ways, considering self-fertilisation and crossfertilisation as two possible modes of reproduction.

Gross reproductive rate (GRR) is the number of eggs produced by the survivors and calculated as

$$
G R R=\sum_{x=0}^{y} m_{x} .
$$

Net reproductive rate $\left(\mathrm{R}_{0}\right)$ is the number of females produced per female during its life and calculated as

$$
R_{0}=\sum_{x=28}^{126} l_{x} \cdot m_{x},
$$

where $m_{x}$ is the number of females produced per female of age $\mathrm{x}$ (days) (since P. acuta is hermaphrodite, $m_{x}$ was considered equal to all the eggs oviposited at age $x$, without division as male and female). The cohort generation time, $T_{\mathcal{l}}$, was calculated as $T_{c}=\sum x \cdot l_{x} \cdot m_{x} / R_{0}$ and the intrinsic rate of population increase $\left(r_{m}\right)$ was obtained as $r=\frac{\sum l_{x} m_{x} \log _{e} \sum l_{x} m_{x}}{\sum x l_{x} m_{x}}$.

Thus an age-specific life table was constructed in lieu of stage-specific life table because only adult stages were considered. Whilst stage-specific life table is a better predictor of life history features, the age-specific life table is more suitable for field studies. The data of the experiments were subjected to statistical analysis (Zar, 1999) using XLSTAT software (Addinsoft, 2010). Selection of the statistical tests was made following Krebs (1999) and Zar (1999).

\section{Results}

The individuals of the cohort showed varying degree of longevity with a maximum period of survival being 133 days. The survivorship pattern and the life expectancy of the P. acuta are shown in Fig. 1. The age-specific survivorship (s) was 0.825 (calculated by the slope of the regression line $\ln \left(l_{x}\right)$ on $x$; Fig 3b), whilst the mean life expectancy was $4.21 \pm 0.33$ weeks. In all the cohorts, the longevity of the snails remained between 4 and 133 days post hatching with the age at first reproduction (day of first oviposition) ranging between 28 and 42 days. At the time of reproductive maturity, the snails were on an average $6 \mathrm{~mm}$ in shell length and $23.5 \mathrm{mg}$ in body weight. The growth of the
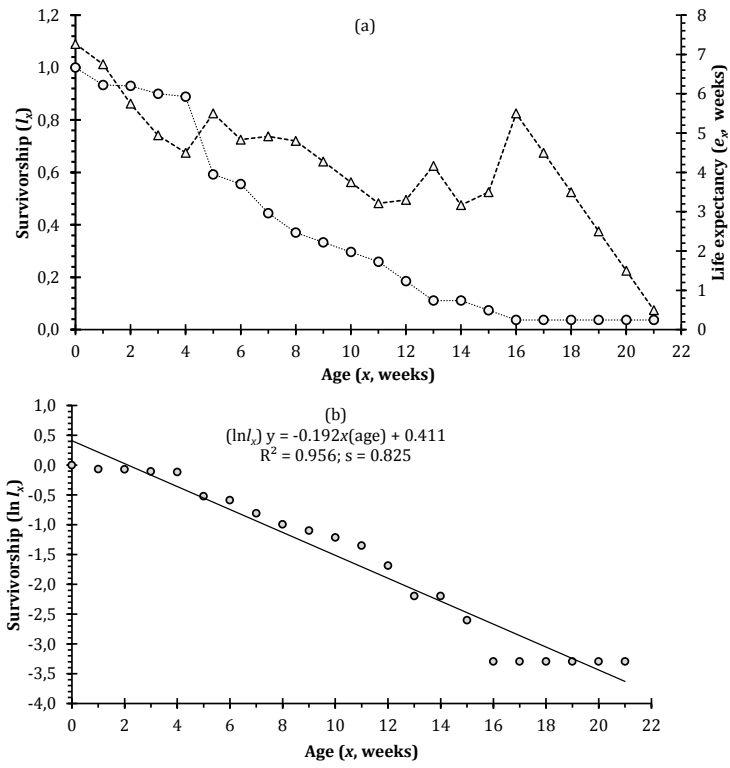

Fig. 1. (a) The survivorship and life expectancy and (b) the agespecific survivorship of the snail $P$. acuta reared under laboratory condition, initial collection of the snails was made from the newly colonised habitat in Burdwan, West Bengal, India. 

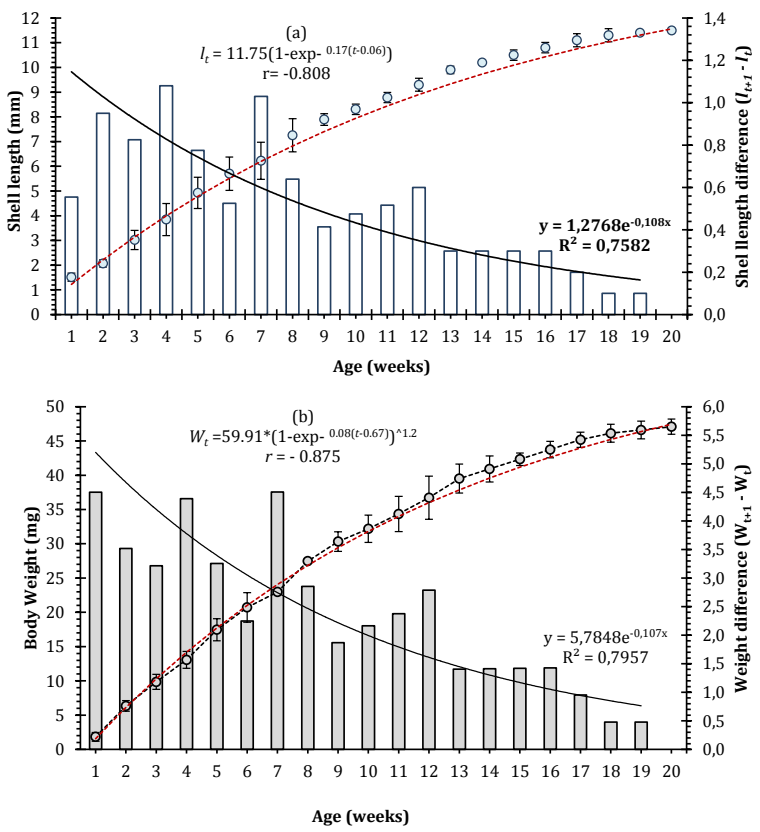

Fig. 2. The growth of the snail P. acuta in terms of (a) shell length and (b) body weight measured weekly. Filled circles represent values in specific week, the dashed line represent the expected values following the von Bertalanffy growth equation. Weekly changes in length and weight are represented through the bars. The respective regression equations of the growth increment as a function of time are shown in the figures for the shell length $\left(l_{t}=11.75\left(1-\exp ^{-0.17(t-0.06)}\right)\right)$ and for the body weight $\left(\mathrm{W}_{\mathrm{t}}=59.91^{\star}\left(1-\exp ^{-0.08(\mathrm{t}-0.67)}\right)^{\wedge 1.2}\right)$.

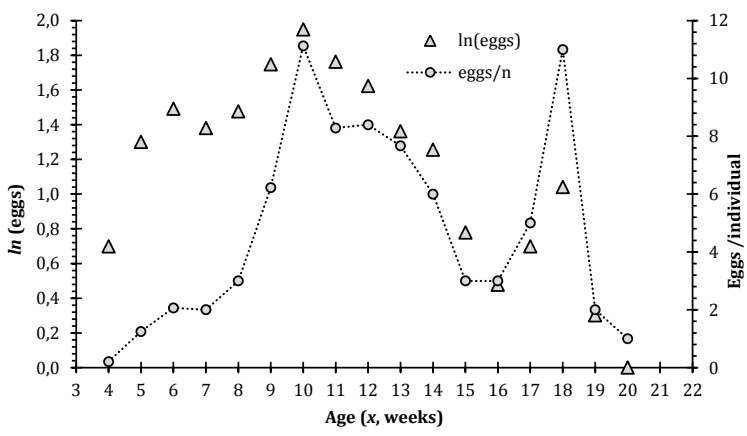

Fig. 3. The number of eggs and the eggs per individual of $P$. acuta collected from newly colonised habitats in Burdwan, West Bengal, India. snails shown through the changes in shell length over the time period (Fig. 2) complied with the von Bertalanffy growth equation significantly reflected through high correlation values in the differences in the shell length and the observed shell length $(r=-0.808$; $d f=19)$ over the time period. Changes in the shell length, however, were a decreasing function of time period, following a power regression equation (Fig. 2). Comparison of the observed and expected $l_{t}$ values did not show significant differences indicating fit of the growth curve with the von Bertalanffy equation (difference $=$ 0.236 ; observed $\mathrm{z}$ score $=0.230 ; P=$ $0.818 ; n=20$ paired data). Changes in the biomass and the observed biomass were significantly negatively correlated $(r=-0.875 ; d f=$ 19), and similar to the shell length, the body weight was a decreasing function of time period (Fig. 2). In the subsequent weeks, the increase in body weight of the snails complied with the von Bertalanffy growth equation with the expected and the observed biomass did not differ significantly(difference $=0.376$; observed $\mathrm{z}$ score $=0.083$; $P=0.934)$ (Fig. 2).

The number of egg capsules oviposited during the reproductive period varied amongst the weeks, with the number of eggs per capsule ranging between 1 and 11 . The total number of eggs oviposited in a week varied between 1 and 89 , with a peak during the middle of the repro- 
ductive period. In correspondence to the survivors, the eggs per capsules varied during the reproductive period between 1 and 11.13 (Fig. 3). Assuming the hermaphroditic nature and self-fertilisation by $P$. acuta, the net reproductive rate was observed to be 116.07 and the cohort generation time to be 46.95 . The intrinsic rate of increase $\left(r_{m}\right)$ was estimated to be 0.1 , whilst the finite rate of increase $(\lambda)$ was 1.11 (Table 1 ).

T a b l e 1 . The fecundity schedule of the $P$. acuta reared under laboratory condition for the estimation of the generation time and fecundity. The eggs of P-generation population collected from a newly colonised population in Burdwan, West Bengal, India.

\begin{tabular}{|c|c|c|c|c|}
\hline $\boldsymbol{x}$ (age, in weeks) & $\mathbf{l}_{\mathbf{x}}$ & $\mathbf{m}_{\mathbf{x}}$ & $\mathbf{1}_{\mathbf{x}} \mathbf{m}_{\mathbf{x}}$ & $\mathbf{x l}_{\mathbf{x}} \mathbf{m}_{\mathbf{x}}$ \\
\hline 4 & 0.8 & 5 & 4 & 10 \\
\hline 5 & 0.53 & 20 & 10.67 & 213.33 \\
\hline 6 & 0.5 & 31 & 15.5 & 480.5 \\
\hline 7 & 0.4 & 24 & 9.6 & 230.4 \\
\hline 8 & 0.33 & 30 & 10 & 300 \\
\hline 9 & 0.3 & 56 & 16.8 & 940.8 \\
\hline 10 & 0.27 & 89 & 23.73 & $2,112.27$ \\
\hline 11 & 0.23 & 58 & 13.53 & 784.93 \\
\hline 12 & 0.17 & 42 & 7 & 294 \\
\hline 13 & 0.1 & 23 & 2.3 & 52.9 \\
\hline 14 & 0.1 & 18 & 1.8 & 32.4 \\
\hline 15 & 0.07 & 6 & 0.4 & 2.4 \\
\hline 16 & 0.03 & 3 & 0.1 & 0.3 \\
\hline 17 & 0.03 & 5 & 0.17 & 0.83 \\
\hline 18 & 0.03 & 11 & 0.37 & 4.03 \\
\hline 19 & 0.03 & 2 & 0.07 & 0.13 \\
\hline 20 & 0.03 & 1 & 0.03 & 0.03 \\
\hline & & $R_{o}$ & 116.07 & $5,449.3$ \\
& & $T_{c}$ & 46.95 & \\
\hline & & $r_{m}$ & 0.10 & \\
\hline
\end{tabular}

\section{Discussion}

The life history features particularly the aspects of fecundity are crucial in successful colonisation and establishment of invasive freshwater snails. Reproduction and growth of the early colonisers determine the pace of establishment of the freshwater snails in the newer habitats (Keller et al., 2007; Gherardi, 2007; Nentwig, 2008). Although invasion of the freshwater snails is facilitated by diverse mechanism, establishment and habitat expansion at the local and regional scales are dependent on the growth and reproductive ability of the concerned species. Theoretical explanations for the risk associated with the invasion of the freshwater species identified growth and fecundity as major factors for colonisation, establishment and range expansion in the newer geographical regions. Empirical studies on the invasion biol- 
ogy of the freshwater snails Melanoides tuberculata (Elkarmi, Ismail, 2007); Bellamya chinensis (Stephen et al., 2013), Physa acuta (de Kock, Wolmarans, 2007; Semenchenko et al., 2008; Guo et al., 2009; Ng et al., 2015), Pomacea canaliculata (de Brito, Joshi, 2016) and P. insularum (Conner et al., 2008) suggest that growth and reproduction are crucial indicators for colonisation and establishment in the invaded habitats. As a consequence, evaluation of the growth and reproductive features of the invasive species has been carried out to predict the prospective habitat expansion in the concerned regions. The impact of the invasive snails on the native biota and ecosystem functions is also linked with the growth and reproductive performances in the invaded habitats. Assessment of the growth and reproduction through the life table studies is, therefore, significant for invasive freshwater snails such as Physa acuta.

Although the shell length and body weight increments were higher for P. acuta observed in the present instance, the pattern of growth remained similar to those occurring in Argentina (Núñez, 2010, 2011). In comparison to the survival till 88 weeks with a maximum shell length of $9.08 \mathrm{~mm}$ observed in Argentina, the P. acuta in the present study survived for 22 weeks but attended a shell length of $11.5 \mathrm{~mm}$ (and body weight of $47.08 \mathrm{mg}$ ). Amongst the many possible reasons, the faster growth of $P$. acuta can be attributed to the temperature condition, which was more than $27{ }^{\circ} \mathrm{C}$, in contrast to $24^{\circ} \mathrm{C}$ for the conditions in Argentina (Núñez, 2011). The growth and survivorship of $P$. acuta in the present instance are more similar to the observations made on the populations of South Africa (Brackenberry, Appleton, 1993) reared at a constant temperature of $25{ }^{\circ} \mathrm{C}$. The temperature-dependent variation observed in the South African population of $P$. acuta is similar to those observed in the two indigenous snails Lymnaea luteola and Indoplanorbis exustus (Aziz, Raut, 1996). Under laboratory culture, the snails Lymnaea luteola $(1.23 \mathrm{~mm}$ and $18.63 \mathrm{mg}$ of shell length and body weight) and Indoplanorbis exustus $(0.78 \mathrm{~mm}$ in shell diameter and $31.2 \mathrm{mg}$ body weight) exhibited higher increment (per week) than Physa acuta ( $0.52 \mathrm{~mm}$ shell length and $2.38 \mathrm{mg}$ body weight), under similar temperature conditions. In comparison with Lymnaea luteola (37 days) and Indoplanorbis exustus (69 days), Physa acuta attained sexual maturity between 28 and 32 days. In contrast to the eggs produced by an individual Lymnaea luteola (0.25-443.67) and Indoplanorbis exustus (7.55-17.5), Physa acuta produced comparatively low number (0.2-11.2 eggs/individual) for a greater time period of 22 weeks (Lymnaea luteola, 16weeks; Indoplanorbis exustus,17weeks) (Raut, Misra, 1993; Misra,Raut, 1993).The intrinsic rate of increase, the finite rate of increase and the generation time of the Physa acuta observed in the present instance corroborate with the observations made in the South Africa population (Brackenberry, Appleton, 1993) when the temperature regime of the culture is considered to be $25^{\circ} \mathrm{C}$.

Invasion of the freshwater habitats by the snail P. acuta may elicit competition with the indigenous snails such as Lymnaea luteola, Indoplanorbis exustus and Gyraulus convexiusculus in the concerned geographical region, because the resource requirements and the life history attributes are considerably similar. However, the freshwater habitats in Burdwan, West Bengal, and similar regions in India, the natural enemies of the snails are quite common. Earlier studies suggest that the malacophagous leech Glossiphonia weberi (Aditya, Raut, 2002a) and the water bug Diplonychus (=Sphaerodema) rusticus (Aditya, Raut, 2002b,c) are the potential predators of Physa acuta. The vulnerability of the snail $P$. acuta remained no different from 
the indigenous snail Lymnaea luteola, when both the snail species were exposed to the water bugs under laboratory conditions (Aditya, Raut, 2002c). Therefore, colonisation and establishment of the invasive snail Physa acuta in the freshwater habitats of West Bengal, India, would require evasion strategies against the natural enemies. The freshwater habitats in the study areas are featured by the presence of ampullariid, viviparid, lymnaeid and planorbid snails, but no physid snails (Banerjee et al., 2010; Kundu et al., 2014). In the sewage drains and associated ditches, the snails Lymnaea luteola and Physa acuta have been noticed to co-occur, providing evidence of coexistence of indigenous and invasive species in the same habitat. Further studies are required to assess the colonisation prospects of $P$. acuta in other freshwater habitats in the area as well as predict the invasion impact on the indigenous biota. Whilst the present study provides a primary description of the life cycle of the invasive snail, the steps for population intervention using natural enemies should be framed to prevent the invasion of the snail in the natural habitats.

\section{Acknowledgements}

The authors are grateful to the respective Heads Department of Zoology, The University of Burdwan, Burdwan, and University of Calcutta, Kolkata, India, for the facilities provided including DST-FIST. The first author, CS, and the second author, SP, acknowledge the financial assistance through fellowship under Rajiv Gandhi National Fellowship (UGC) and Maulana Azad National Fellowship (UGC), respectively, in carrying out the work.

\section{References}

Addinsoft SARL (2010). XLSTAT software, version 9.0. Paris: Addinsoft.

Aditya, G. \& Raut S.K. (2001a). Food of the snail, Pomacea bridgesi introduced in India. Curr.Sci., 80,919-921.

Aditya, G. \& Raut S.K. (2001b). Predation of water bug Sphaerodema rusticum Fabricius on the snail Pomacea bridgesi (Reeve), introduced in India. Curr. Sci., 81,1413-1414.

Aditya, G. \& Raut S.K. (2002a). Potential of the leech Glossiphonia weberi (Blanchard) in controlling the sewage snails Physa acuta Draparnaud. Curr. Sci., 83(11), 1317-1319.

Aditya, G. \& Raut S.K. (2002b). Predation potential of the water bugs Sphaerodema rusticum on the sewage snails Physa acuta. Mem. Inst. Oswaldo Cruz, 97(4), 531-534.

Aditya, G. \& Raut S.K. (2002c). Predation of water bug Sphaerodema rusticum on the freshwater snails Lymnaea (Radix) luteola and Physa acuta. Veliger, 45(3), 267-269.

Aditya, G. \& Raut S.K. 2005. Feeding of the leech Glossiphonia weberi on the introduced snail Pomacea bridgesii in India. Aquat. Ecol., 39, 465-471. DOI:10.1007/s10452-005-9006-2.

Ali, J.H. (1993). The distribution of Physa acuta Draparnaud (Gastropoda: Physidae) in Malaysia and its suitability as test material for insecticide toxicity studies. J. Med. Appl. Malacol., 5, 129-134.

Appleton, C.C. \& Miranda N.A.F. (2015). Two Asian freshwater snails newly introduced into South Africa and an analysis of alien species reported to date. Afr. Invertebr., 56(1), 1-17. urn:lsid:zoobank.org:pub:CC5D9F728B48-46FF-A9FB-E18E9F568396

Aziz, A. \& Raut S. (1996). Thermal effect on the life-cycle parameters of the medically important freshwater snail species Lymnaea (Radix) luteola (Lamarck). Mem. Inst. Oswaldo Cruz, 91(1), 119-128.

Banerjee, S., Aditya, G., Saha, N. \& Saha G.K. (2010). An assessment of macroinvertebrate assemblages in mosquito larval habitats-space and diversity relationship. Environ. Monit. Assess., 168, 597-611. DOI:10.1007/s10661009-1137-9.

Brackenbury, T.D. \& Appleton C.C. (1993). Recolonization of the Umsindusi River, Natal, South Africa, by the invasive gastropod, Physa acuta (Basommatophora, Physidae). J. Med. Appl. Malacol., 5, 39-44.

Conner, S.L., Pomory, C.M. \& Darby P.C. (2008). Density effects of native and exotic snails on growth in juvenile apple snails Pomacea paludosa (Gastropoda: Ampullariidae): a laboratory experiment. J. Molluscan Stud., 74, 355-362. DOI:10.1093/mollus/eyn024. 
de Brito, F.C. \& Joshi R.C. (2016). The golden apple snail Pomacea canaliculata: A review on invasion, dispersion and control. Outlooks Pest Manage., 27(4), 157-163.

de Kock, K.N. \& Wolmarans C.T. (2007). Distribution and habitats of the alien invader freshwatersnail Physaacuta in South Africa. Water SA, 33, 717-722. DOI:10.4314/wsa.v35i5.49197.

Devi, P., Islam, S. \& Das M. (2006). Prevalence of freshwater snails in Assam. J. Vet. Parasitol., 20(1), 81-84.

Devi, P., Islam, S. \& Das M. (2008). Ecology and biology of aquatic snails and their control: I. Comparative biology and development of five freshwater snails from Assam. J. Vet. Parasitol., 22(2), 9-12.

Elkarmi, A.Z. \& Ismail N.S. (2007). Growth models and shell morphometrics of two populations of Melanoides tuberculata (Thiaridae) living in hot springs and freshwater pools. J. Limnol., 66(2), 90-96. DOI:10.4081/jlimnol.2007.90.

Gherardi, F. (2007). Biological invaders in inland waters: Profiles, distribution, and threats. Dordrecht: Springer.

Gotoh, T. \& Kawata M. (2000). The effects of spatial habitat structure on population variability of freshwater snails. Hydrobiologia, 429, 157-169. DOI:10.1023/A:1004075100758.

Guo, Y., Hwang, C-C. \& He H. 2009. Expansion of an invasive freshwater snail Physa acuta (Gastropoda: Physidae) in China. Molluscan Res., 29, 174-178.

Keller, R.P., Drake, J.M. \& Lodge D.M. (2007). Fecundity as a basis for risk assessment of nonindigenous freshwater Molluscs. Conserv.Biol., 21(1), 191-200. DOI:10.1111/j.1523-1739.2006.00563.x.

Krebs, C.J. (1999). Ecological methodology.New York: Benjamin Cummings.

Kundu, M., Sharma, D., Brahma, S., Pramanik, S., Saha, G.K. \& Aditya G. (2014). Insect predators of mosquitoes of rice fields: portrayal of indirect interactions with alternative prey. J. Entomol. Zool. Stud., 2(5), 97-103. www. entomoljournal.com

Lach, L. \& Cowie R.H. (1999). The spread of the introduced freshwater apple snail Pomacea canaliculata (Lamarck) (Gastropoda: Ampullariidae) on O'ahu, Hawaíi. Bishop Mus. Occas. Pap., 58, 66-71.

Misra, T.K. \& Raut, S.K. (1993). Dynamic of populationdynamics in a medically important snail species Lymnaea (Radix) luteola (Lamarck). Mem. Inst. Oswaldo Cruz, 88, 469-485.

Nentwig, W. (2008). Biological invasions. (Ecological studies vol. 193). Berlin: Springer-Verlag.

Ng, T.H., Tan, S.K. \& Yeo D.C.J. (2015). Clarifying the identity of the long-established, globally-invasive Physa acuta Draparnaud, 1805 (Gastropoda: Physidae) in Singapore. BioInvasion Rec., 4(3), 189-194. DOI:10.3391/ bir.2015.4.3.06.

Núñez, V. (2010). Differences on allocation of available resources, in growth, reproduction, and survival, in an exotic gastropod of Physidae compared to an endemic one. Iheringia Sér. Zool., 100(3), 275-279. DOI:10.1590/S007347212010000300014 .

Núñez, V. (2011). Fecundity and survival advantages of an exotic gastropod compared to a native species. Am. Malacol. Bull., 29, 95-103. DOI:10.4003/006.029.0222.

Raković, M.J., Raković, M.B., Petrović, A.M., Popović, N.Z., Đuknić, J.A., Naunovic, Z.Z. \& Paunović M.M. (2016). Haplotype variation in the Physa acuta group (Basommatophora): genetic diversity and distribution in Serbia. Mediterr. Mar. Sci., 17(1), 292-301.

Raut, S.K. \& Misra T.K. (1993). Influence of salinity on the breeding of three medically important freshwater snail species (Gastropoda: Basommatophora: Lymnaeidae et Planorbidae). Malakol. Abh. (Dresden), 16, 173-176.

Raut, S.K., Bhaumik, S. \& Das S. (1995). Occurrence of the snail Physa acuta Draparnaud in Calcutta, India. Journal of Bombay Natural History Society, 92, 434.

Semenchenko, V., Laenko, T. \& Razlutskij V. (2008). A new record of the North American gastropod Physella acuta (Draparnaud, 1805) from the Neman River Basin, Belarus. Aquat. Invasions, 3, 359-360. DOI:10.3391/ ai.2008.3.3.14.

Stephen, B.J., Allen, C.R., Chaine, N.M., Fricke, K.A., Haak, D.M., Hellman, M.L., Kill, R.A., Nemec, K.T., Pope, K.L., Smeenk, N.A., Uden, D.R., Unstad, K.M., VanderHam, A.E.\& Wong A. (2013). Fecundity of the Chinese mystery snail in a Nebraska reservoir. J. Freshw. Ecol., 28(3), 439-444. DOI:10.1080/02705060.2013.769127.

Zar, J.H. (1999). Biostatistical analysis.New Delhi: Singapore Pte Ltd.

Zukowski, S. \& Walker K.F. (2009). Freshwater snails in competition: alien Physa acuta (Physidae) and native Glyptophysa gibbosa (Planorbidae) in the River Murray, South Australia. Mar. Freshw. Res., 60(10), 999-1005. DOI:10.1071/MF08183. 